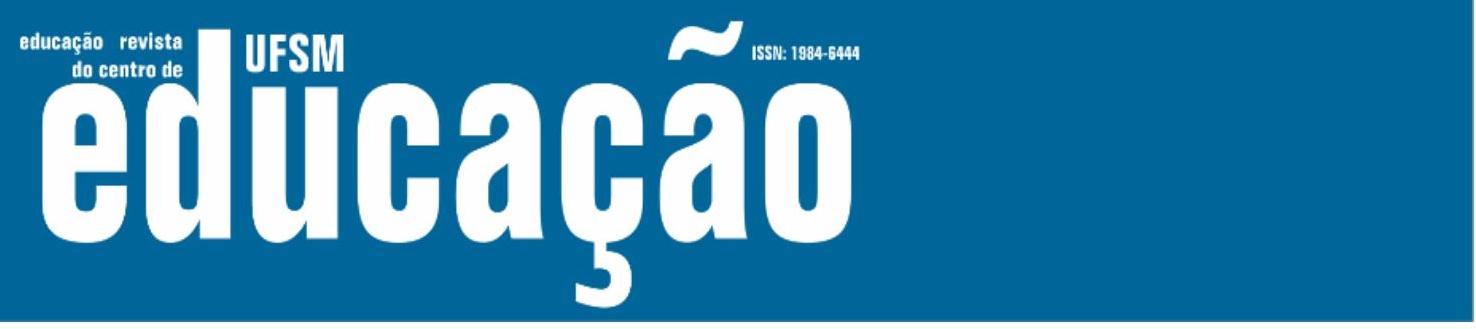

ISSN: 1984-6444 | http://dx.doi.org/10.5902/1984644435265

\title{
O Curso de Pedagogia entre Deliberações
}

\section{The pedagogy course between deliberations}

Adriana Varani

Professora Doutora na Universidade Estadual de Campinas. Campinas, São Paulo, Brasil. avarani@unicamp.br - https://orcid.org/0000-0002-7480-4998

\section{Dirce Zan}

Professora Doutora na Universidade Estadual de Campinas. Campinas, São Paulo, Brasil. dircezan@unicamp.br

\section{Luciane Aparecida Grandin}

Pedagoga da Faculdade de Educação da Universidade Estadual de Campinas. Campinas, São Paulo, Brasil.

Igrandin@unicamp.br

Recebido em 17 de outubro de 2018

Aprovado em 10 de outubro de 2019

Publicado em 31 de janeiro de 2020

\section{RESUMO}

Num contexto de redefinição dos cursos de licenciatura em nível nacional, posicionamentos e concepções distintas são pautadas e entram em disputa. $O$ presente texto tem como objetivo apresentar e refletir sobre uma destas disputas, o processo de regulação dos cursos de licenciatura, mais especificamente o de Pedagogia, no cenário de aprovação da deliberação 111/12 do Conselho Estadual de Educação do Estado de São Paulo. Tal reflexão se dá a partir de nossa experiência como docentes de uma universidade pública paulista. Para tanto iniciamos com a breve contextualização do quadro histórico do referido curso, desde sua fundação com a perspectiva de formação de especialistas, passando pela organização de movimentos de profissionais da educação na luta por uma formação de professores em nível universitário. Com o objetivo de definir uma política para a formação de professores dos anos iniciais e dos anos finais do ensino fundamental das instituições públicas de ensino superior em São Paulo, em 2012 o CEE apresenta uma proposta de deliberação sobre o assunto. Tal apresentação provoca questionamentos diversos, desde o conteúdo voltado para um olhar eminentemente prático para a ação docente, passando pela compreensão de como tal deliberação e o discurso que a acompanhou, via mídia, anunciava uma interferência na autonomia didático-científica da universidade, prevista na Constituição de 1988. Com esta discussão gostaríamos de trazer à tona uma realidade local que reflete e retrata políticas de dimensão nacional no campo da formação de professores.

Palavras-chave: Formação Inicial de Professores; Pedagogia; Autonomia universitária. 


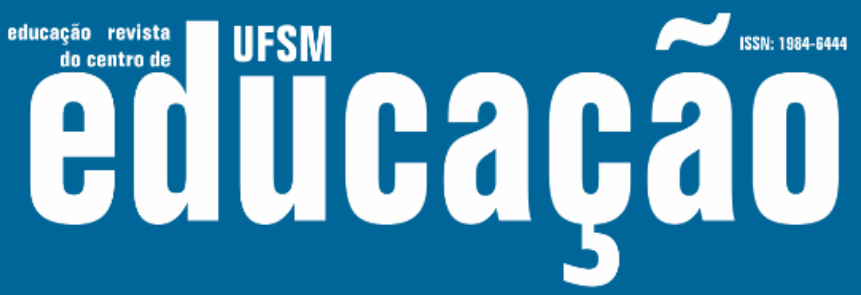

ISSN: 1984-6444 | http://dx.doi.org/10.5902/1984644435265

\section{ABSTRACT}

In a context of redefinition of undergraduate courses at the national level there are distinct positioning and conceptions in Shock. This text aims to present and reflect on the process of regulating the undergraduate courses, more specifically that of pedagogy, in the scenario of approval of the deliberation 111/12 of the State Council of Education of Sao Paulo state. This reflection is given from our experience as professor of a São Paulo state public university. To begin with the brief contextualization of the historical framework of this course, from its foundation with the prospect of training of specialists, through the organization of movements of education professionals in the struggle for a formation of University-level Teachers. With the objective of defining a policy of the public institutions of higher education in Sao Paulo for the formation of teachers for the early and the final years of elementary education, in 2012 the EEC presents a proposal for deliberation on the Subject. Such a presentation raises various questions, from the content focused to an eminently practical look at the teaching action, through the understanding of how such deliberation and the speech that accompanied it, via media, announced an interference in Scientific didactic autonomy of the university, provided for in the Constitution of 1988. With this discussion we would like to bring up a local reality that reflects and portrays policies of a national dimension in the field of teacher Training.

Keywords: Initial teacher training; Pedagogy; University autonomy.

\section{Introdução}

Desde a década de 1990 vivemos um movimento intenso de redefinição dos cursos de graduação no Brasil, em especial dos cursos de formação de professores. Tal movimento se expressa a partir da construção de Diretrizes Curriculares. Essa intensidade é materializada pela necessidade do cuidado em lidar com a questão delicada e premente de melhorias no campo da educação. Esse processo é intenso também por conta de ocorrer num estado democrático que se efetiva através de vias da participação. Torna-se complexo lidar com uma realidade caracterizada pela diversidade, que necessita ser contemplada em suas especificidades. Não somente a diversidade social inspira o processo iniciado nos anos de 1990, mas há também a marca da diversidade teórica na forma de se conceber a formação dos profissionais da educação, expressa nos documentos oficiais divulgados desde então, sejam de autoria de governos ou de entidades do campo educacional, muitos deles em sintonia 


\section{F HEM eltuarao

ISSN: 1984-6444 | http://dx.doi.org/10.5902/1984644435265

com os diferentes movimentos sociais. Como pensar em formação de professores sem relevar questões de desigualdade racial, de gênero, econômica? Sem considerar questões específicas no campo dos estudos da educação especial, dos conhecimentos básicos necessários que circulam no cotidiano escolar? Como não se pautar por conhecimentos teóricos de áreas como psicologia, história, sociologia, filosofia e acima de tudo, por conhecimentos pedagógicos em constante reconstrução e diversamente produzidos?

Nesse processo, é fundamental considerar as relações de poder e os diferentes interesses vinculados ao sistema econômico em que vivemos, especialmente financeiros e empresariais que exercem forte pressão sobre as políticas educacionais.

Neste conjunto de intensidades vividas para a construção de regulamentações e diretrizes dos cursos de formação de professores, diferentes narrativas são construídas e entram em conflito. É a partir de uma delas que desenvolveremos este texto. A construção de uma narrativa da produção da deliberação do Conselho Estadual de Educação de São Paulo sob número 111/12.

Esta narrativa se constrói no lugar que ocupamos: docentes de cursos de formação de professores de uma universidade pública paulista. Lembramos Bourdieu (2005, p. 15) quando em sua obra "Esboço de uma Auto Análise", assume que escolhas e história de vida estão intrinsicamente relacionadas às suas análises sociológicas e afirma "compreender é, em primeiro lugar, compreender o campo em que nos fizemos e contra o qual nos fizemos". O que nos motivou a escrita deste texto foi a necessidade de ampliar a discussão sobre o processo de busca pela qualidade no campo da formação de professores. Estão em jogo diferentes e opostas perspectivas sobre o que é esta qualidade, neste texto apresentamos duas perspectivas - uma é a defesa pela formação prática e técnica e outra pela formação ampla, que se paute pela postura da curiosidade epistemológica, por um discurso que não dissocie teoria e prática.

Iniciamos a escrita a partir de uma retomada histórica sobre a configuração da discussão em torno de defesas distintas do curso de Pedagogia, para em seguida apresentar o processo de recontextualização da Deliberação do Conselho Estadual de Educação de São Paulo (CEE 111/12) no interior da universidade. E por fim, 


\section{Autนaดูลิ}

ISSN: 1984-6444 | http://dx.doi.org/10.5902/1984644435265

apontamos alguns aspectos relacionados aos princípios que circulam na experiência vivida com a deliberação.

\section{Que sabemos sobre a produção histórica do curso de Pedagogia?}

Na nossa perspectiva, é fundamental que o tema em debate seja analisado de forma contextualizada, viabilizando assim sua compreensão e discussão. No caso específico, torna-se necessário o entendimento de que o assunto não se esgota no tempo presente, mas que muita luta se travou ao longo dos anos.

O primeiro curso de Pedagogia no Brasil foi implementado em 1939 no bojo da criação da Faculdade Nacional de Filosofia, que tinha como objetivo ser o estabelecimento federal destinado à preparação do magistério secundário, de acordo com Saviani (2008). Uma das principais características dos cursos de formação no ensino superior neste momento é o famoso $3+1$. Três anos de bacharelado, somado a um ano de curso de didáticas que licenciaria o estudante no trabalho como professor de escolas secundárias.

Segundo Saviani (2008), naquele momento o curso de bacharelado em Pedagogia formava o técnico em educação e tinha caráter generalista. Para o autor, a configuração do curso era restritiva, à medida que assim se caracterizava. Dessa forma, o currículo estabelecido encaminhava uma formação voltada para o desenvolvimento acadêmico da área de educação e com pouca inserção no trabalho pedagógico realizado na e pela escola, especialmente no cotidiano da aula e no processo ensino aprendizagem. Diferentes posicionamentos sobre o papel do curso de Pedagogia vão se delineando e contribuindo para a ampliação do debate, incluindo a necessária compreensão das especificidades dos papéis desenvolvidos pelo profissional da educação no contexto educacional. O caráter generalista do curso permaneceu até 1968. O esquema 3+1 é considerado ultrapassado e definida por lei a sua necessária superação. No entanto, é possível observarmos que ele continua presente ainda hoje na concepção da formação, preservado através da dicotomia existente entre bacharelado e licenciatura (SAVIANI, 2008). A fragmentação não está 


\section{HEM oltuará

ISSN: 1984-6444 | http://dx.doi.org/10.5902/1984644435265

expressa necessária e restritivamente através da organização curricular, mas também nas concepções que orientam os cursos e os sujeitos que neles atuam.

Em 1969, após a Reforma Universitária, uma nova resolução (252/69) do Conselho Federal de Educação (CFE) "fixa os mínimos de conteúdo e duração a serem observados na organização do curso de Pedagogia". Neste momento aparecem as habilitações no campo educacional e na formação do Pedagogo. As habilitações que são implementadas não se referem à docência como professor do antigo ensino primário e pré-escolar, mas referem-se à formação técnica, de especialistas da educação (orientação educacional; administração escolar; supervisão escolar; inspeção escolar), bem como à docência de disciplinas pedagógicas do antigo curso normal. O professor do ensino fundamental e da educação infantil eram formados nos cursos normais. Tal assunção das habilitações, a formação para especialista ou docência em curso normal, no nível médio passou a ser entendida como "quem pode mais, pode menos", e os profissionais formados no curso de Pedagogia poderiam então, atuar também como professores do ensino fundamental.

A partir da década de 1980, no bojo das mobilizações coletivas e populares para a discussão de rumos e políticas para a educação pública em diferentes campos, a reflexão sobre a formação inicial de professores intensifica-se.

Scheibe (1999) nos lembra sobre o início do debate

Nos debates sobre o curso de pedagogia que vem ocorrendo desde o final da década de 1970, uma temática central sempre esteve em forma: a questão da base comum nacional. Essa expressão foi cunhada pelo Movimento Nacional de Formação do Educador, e explicitada pela primeira vez no Encontro Nacional para a "Reformulação dos Cursos de Preparação de Recursos Humanos para a Educação", realizado em Belo Horizonte, em novembro de 1983, justo no momento em que as forças sociais empenhadas na luta pela redemocratização do pais estavam se organizando em todos os campos, inclusive no campo educacional. (...) No plano nacional, os educadores engajavam-se na luta pela reformulação do curso de pedagogia e das licenciaturas, contrapondo-se à imposição de reformas definidas nas instâncias oficiais. (SCHEIBE, 1999, p. 226)

No período citado pela autora, há a criação da Comissão Nacional de Reformulação dos Cursos de Formação de Educadores (Conarcfe), que a partir de 1990 ampliou-se e se constitui na Associação Nacional de Formação dos Profissionais 


\section{F HEM olduarato

ISSN: 1984-6444 | http://dx.doi.org/10.5902/1984644435265

da Educação (ANFOPE). A defesa da base comum nacional na formação de professores tinha como perspectiva, em síntese, tomar a docência como fio condutor, a partir de três dimensões: política, profissional e epistemológica. Sem nos alongar demasiado neste aspecto, estas dimensões se articulavam no sentido de permitir que o profissional se apropriasse, de forma articulada, da totalidade do trabalho a ser exercido na realidade da escola pública brasileira e em outros espaços em que pudesse contribuir como profissional e educador. Tal definição está no documento final do Encontro Nacional desta Comissão. ${ }^{1}$

A articulação do trabalho docente não implica em se restringir aos aspectos relacionados à metodologia usada e ao que se ensina na sala de aula. Dentre outras defesas, neste momento o que se pautava para cursos de formação de professores era uma necessária compreensão da articulação entre as categorias conteúdo/método e teoria/prática, que explicitasse as relações de dependência epistemológicas entre método e conteúdo específico, as formas ideológicas veiculadas nos materiais didáticos, a organização do trabalho docente e da própria escola. Além disto, estava comprometida com a formação de alunos e professores pesquisadores, com ênfase na categoria da prática social. Defendia-se desde este momento que a formação docente deveria ocorrer na universidade, onde haveria espaço para associar uma base teórica sólida, articulada à pesquisa e ao trabalho pedagógico das instituições de educação pública. Neste contexto a centralidade é a atuação no magistério e a preparação para ação como especialista do campo educacional de forma articulada entre si.

Ao longo deste processo, o que percebemos é uma proposta que supera dois extremos que representavam os cursos predominantes à época: o curso de Pedagogia e os cursos de habilitação específica para o magistério, antigos cursos normais de segundo grau. A primeira proposta é que a Pedagogia se firmava pela formação de especialistas, que não tinham centralidade nos processos pedagógicos intra-escolares, se firmava pela assunção da formação de profissionais que trabalhariam com administração, supervisão, orientação escolar, ou seja, que trabalhariam com o planejamento educacional. Aos cursos, simplificadamente 


\section{工 Wism

ISSN: 1984-6444 | http://dx.doi.org/10.5902/1984644435265

chamados de magistério, firmava-se por uma perspectiva predominantemente prática, de formação de professores do antigo primário e pré-escola.

Em 1996, a despeito dos movimentos de estudo e reflexões intensas sobre a temática, a LDB 9394/96 é promulgada e nela há a determinação da criação dos Institutos Superiores de Educação, lócus privilegiado para formação de professores. Institui-se o Curso Normal Superior que se configuraria como uma versão do normal secundário no ensino superior.

Os Institutos Superiores de Educação manterão:

I - cursos formadores de profissionais para a educação básica, inclusive o curso normal superior, destinado à formação de docentes para a educação infantil e para as primeiras séries do ensino fundamental;

II - programas de formação pedagógica para portadores de diplomas de educação superior que queiram se dedicar à educação básica;

III - programas de educação continuada para os profissionais da educação dos diversos níveis. (BRASIL, 1996)

Institui-se, então, a possibilidade de ter um curso eminentemente prático, em instituições que não, necessariamente, teriam a possibilidade de articulação entre ensino e pesquisa. A formação assim desenhada poderia viabilizar cursos mais aligeirados e ofertados com um custo menor. (SHEIBE, 2007).

Entre 1996 até 2005 aconteceram diversas mobilizações e debates intensos sobre o projeto do curso de Pedagogia, o que resultou na definição das Diretrizes Curriculares. A partir do que vinha sendo postulado pela LDB, uma proposta era a de transformar os cursos de Pedagogia numa versão mais identificada com o Curso Normal Superior, por outro lado, parte da comunidade acadêmica e movimentos pela formação de professores, defendiam os princípios da Base Nacional Comum e da docência como eixo central da formação.

Segundo Scheibe (2007) a proposta das Diretrizes Curriculares

apresenta uma concepção de docência em que as funções do professor se estendem para além do magistério, abrangendo igualmente a gestão e a pesquisa como instrumento de produção e difusão do conhecimento. Com tal entendimento, não faz sentido nesta formação manter a histórica dicotomia entre bacharelado e licenciatura. (SCHEIBE, 2007, p.50)

A autora se pauta em documentos da ANFOPE para afirmar que o curso ao formar 
ISSN: 1984-6444 | http://dx.doi.org/10.5902/1984644435265

o profissional da educação para atuar no ensino, na organização e gestão de sistemas, unidades e projetos educacionais e na produção e difusão do conhecimento, em diversas áreas da educação é, ao mesmo tempo, uma licenciatura - formação de professores - e um bacharelado - formação de educadores/cientistas da educação. (ANFOPE, 1998, apud SCHEIBE, 2007, p. 50)

Em 2006 são aprovadas as Diretrizes Curriculares Nacionais para o Curso de Pedagogia que, em parte, atendem ao que os movimentos vinham estudando, discutindo e defendendo para a formação de professores. Este documento amplia a concepção dessa formação tomando como base a docência, como defendiam movimentos sociais, e sinalizando que a docência não se restringe à atuação técnica em aula. Passou a contemplar "integradamente à docência, a participação da gestão e avaliação de sistemas e instituições de ensino em geral, a elaboração, a execução, o acompanhamento de programas e atividades educativas" (BRASIL, 2005, p.6), conforme consta no parecer emitido pelo CNE. Tais Diretrizes também deixavam uma grande margem para o trabalho de formação na universidade, tanto no que se refere à relação ensino, pesquisa e extensão, quanto à sua garantia da autonomia universitária didática e científica.

Por outro lado, Scheibe (2007) também alerta que é possível construir certa interpretação baseada no praticismo, quando se assume a prática da docência como base e não a aprofunda, conforme o movimento já sinalizou ao longo de sua história.

A prática da docência como base, segundo Kuenzer e Rodrigues (2006), corre o risco de ser "uma expressão da epistemologia da prática". Decorre daí o grande desafio que precisa ser enfrentado para que esta prática venha a se constituir, nos projetos pedagógicos de curso, no princípio educativo gramsciano: o desafio é estabelecer uma formação teórica sólida, com base no conhecimento científico e na pesquisa consolidada, e não ceder à incorporação da racionalidade técnica ou do praticismo pedagógico predominante na epistemologia da reforma educacional oficial, na qual se vincula o conhecimento formativo a uma prática imediatista. (SCHEIBE, 2007, p.60)

Para além das Diretrizes do curso de Pedagogia, em 2015 foram definidas as Diretrizes Curriculares Nacionais para a Formação Inicial e Continuada dos Profissionais do Magistério da Educação Básica, aprovada pelo CNE no Parecer CNE/CP 02/2015, que de alguma forma, dialogam com aspectos das Diretrizes do 


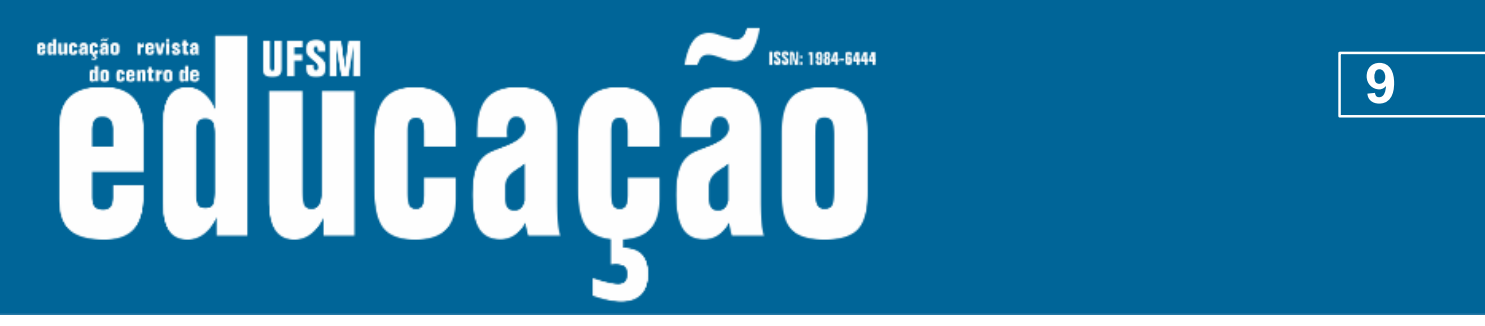

ISSN: 1984-6444 | http://dx.doi.org/10.5902/1984644435265

Curso de Pedagogia, tendo a docência como um dos aportes importantes para a formação. Para além desta relação, e segundo Dourado (2015)

\begin{abstract}
Merece ser ressaltado que as deliberações da Conae cumpriram papel singular nesse processo ao destacar a articulação entre Sistema Nacional de Educação, as políticas e a valorização dos profissionais da educação, bem como ao reafirmar uma base comum nacional para a formação inicial e continuada cujos princípios devem ser considerados na formulação dos projetos institucionais de formação inicial e continuada - incluindo a licenciatura - por meio da garantia de concepção de formação pautada tanto pelo desenvolvimento de sólida formação teórica e interdisciplinar em educação de crianças, adolescentes, jovens e adultos(as) e nas áreas específicas de conhecimento científico quanto pela unidade entre teoria e prática e pela centralidade do trabalho como princípio educativo na formação profissional, como também pelo entendimento de que a pesquisa se constitui em princípio cognitivo e formativo e, portanto, eixo nucleador dessa formação. Importante ressaltar que tais concepções, historicamente, vêm sendo defendidas por entidades da área, especialmente, Anfope, Anpae, Anped, Cedes e Forumdir. (DOURADO, 2015, p. 301)
\end{abstract}

As diretrizes não se restringem à formação inicial, mas apontam para uma política articulatória entre esta e a formação continuada, bem como para princípios de valorização profissional. Vale ressaltar alguns aportes e concepções fundamentais para a melhoria da formação de educadores e suas dinâmicas formativas, constantes das Diretrizes e que provocarão o diálogo que pretendemos estabelecer com a deliberação do Conselho Estadual de Educação de São Paulo (CEE/SP).

6. Os princípios que norteiam a base comum nacional para a formação inicial e continuada, tais como: a) sólida formação teórica e interdisciplinar; b) unidade teoria-prática; c) trabalho coletivo e interdisciplinar; d) compromisso social e valorização do profissional da educação; e) gestão democrática; f) avaliação e regulação dos cursos de formação;

7. A articulação entre graduação e pós-graduação e entre pesquisa e extensão como princípio pedagógico essencial ao exercício e aprimoramento do profissional do magistério e da prática educativa;

8. A docência como ação educativa e como processo pedagógico intencional e metódico, envolvendo conhecimentos específicos, interdisciplinares e pedagógicos, conceitos, princípios e objetivos da formação que se desenvolvem na socialização e construção de conhecimentos, no diálogo constante entre diferentes visões de mundo;

9. O currículo como o conjunto de valores propício à produção e à socialização de significados no espaço social e que contribui para a construção da identidade sociocultural do educando, dos direitos e deveres do cidadão, do respeito ao bem comum e à democracia, às práticas educativas formais e não formais e à orientação para o trabalho;

10. A realidade concreta dos sujeitos que dão vida ao currículo e às instituições de educação básica, sua organização e gestão, os projetos e cursos de formação, devem ser contextualizados no espaço e no tempo e atentos às características das crianças, adolescentes, jovens e adultos que justificam e instituem a vida da/e na escola, bem como, possibilitar a

Educação | Santa Maria | v. 45 |2020

Disponível em: https://periodicos.ufsm.br/reveducacao 


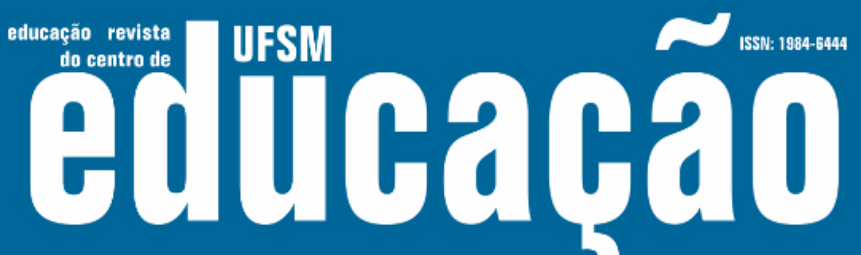

ISSN: 1984-6444 | http://dx.doi.org/10.5902/1984644435265

compreensão e reflexão sobre as relações entre a vida, o conhecimento, a cultura, o profissional do magistério, o estudante e a instituição;

13. O trabalho coletivo como dinâmica político-pedagógica que requer planejamento sistemático e integrado. (BRASIL, 2015, p2)

Estes princípios que fundamentam a concepção de prática docente como base da formação do profissional da educação e os aportes das diretrizes contidas no parecer CNE/CP 02/2015, serão objeto de diálogo com o próximo tópico, a saber a narrativa do CEE $111 / 12$ de SP.

\section{A narrativa da deliberação CEE 111/12}

Ao longo do movimento histórico descrito anteriormente, percebe-se a consolidação de posicionamentos distintos, no que se refere aos princípios que fundamentem a formação de professores. Por causa desses princípios é que em 2011 o Conselho Estadual de Educação do Estado de São Paulo apresentou a Deliberação 111/12, que "Fixa Diretrizes Curriculares Complementares para a Formação de Docentes para a Educação Básica nos Cursos de Graduação de Pedagogia, Normal Superior e Licenciaturas, oferecidos pelos estabelecimentos de ensino superior vinculados ao sistema estadual". Ela tem como objetivo definir uma política para a formação de professores dos anos iniciais e dos anos finais do ensino fundamental das instituições públicas de ensino superior em São Paulo.

Importante lembrar que o CEE legisla, dentre outras matérias, sobre a adequação dos cursos de graduação das universidades públicas estaduais e fundações municipais, às exigências legais das áreas específicas.

A deliberação CEE 111/12 apresentava, inicialmente, alguns aspectos que foram amplamente rechaçados pelas universidades públicas de São Paulo, em especial no que se refere a dois temas. O primeiro deles é o tom de definição curricular dos cursos, o que coloca em questão a autonomia universitária. A esse respeito e outras questões de contexto, podemos retomar o discurso de uma reportagem da Folha de São Paulo sobre a definição das Diretrizes. As ações do CEE são facilmente interpretadas como iniciativas que provocam uma interferência na autonomia universitária conquistada há décadas. Uma das representações desta interferência 


\title{
T Wsm Eutoabुa
}

ISSN: 1984-6444 | http://dx.doi.org/10.5902/1984644435265

está refletida pela manchete da reportagem da Folha de São Paulo de 24 de maio de 2014 - "Conselho impõe (grifo nosso) mais aula prática na pedagogia de USP, Unesp e Unicamp". A reportagem assim inicia seu discurso "O Conselho Estadual de Educação decidiu obrigar (grifo nosso) USP, Unesp e Unicamp a mudarem seus currículos dos cursos de pedagogia e licenciatura, que formam professores para o ensino básico". A produção semântica não deixa dúvidas de que ao Conselho Estadual de Educação interessa determinar, impor, obrigar. Estes são verbos que não cabem à conquista da autonomia universitária no artigo 207 da Constituição Federal de 1988.

Conforme previsto no referido artigo constitucional, as Universidades gozam de autonomia didático-científica, administrativa e de gestão financeira e patrimonial. Prevê ainda o artigo, que essa é uma instituição que deverá atuar de forma indissociável, no ensino, pesquisa e extensão. Simon Schwartzman, em texto publicado no jornal Folha de São Paulo à época da promulgação da Constituição (12 de dezembro de 1988), afirma que a autonomia didático-científica da universidade compreende a

\begin{abstract}
...plena liberdade de definir currículos, abrir e fechar cursos, tanto de graduação quanto de pós-graduação e de extensão. Elas devem ter, também, plena liberdade de definir suas linhas prioritárias e mecanismos de financiamento da pesquisa, conforme regras internas. É fundamental, em relação a este ítem, garantir a autonomia das universidades em relação a órgãos externos como os conselhos nacionais e estaduais de educação, conselhos profissionais e conselhos de pesquisa. Todos estes órgãos devem poder, em qualquer tempo, avaliar e opinar sobre os trabalhos desenvolvidos pelas universidades; mas estas apreciações não poderão ter força decisória ou de autorização sobre o que e como as universidades devem ou não pesquisar e ensinar. Isto significa, por exemplo, que as universidades não estarão mais presas a currículos mínimos de qualquer tipo. Desta forma, os conselhos profissionais deverão buscar novas formas de autorização para o exercício profissional (através de exames de ordem, ou acreditação de determinados cursos), que até hoje decorriam de forma automática da simples posse de diplomas universitários. (SCHWARTZMAN,1988)
\end{abstract}

A conquista constitucional da autonomia universitária gerou, desde então, um amplo debate acerca de sua concepção e formas de garanti-la. Cury (1991, p 26), em artigo clássico, ao demonstrar a relação entre o conceito de autonomia e o espaço da universidade, vai nos lembrar que esta, vinculada à concepção de universitas, é lugar onde se insta "o desvelamento mais universal das coisas(...) e é compreendida como 


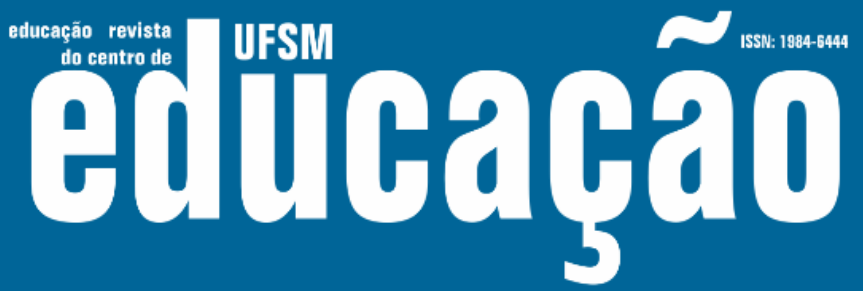

ISSN: 1984-6444 | http://dx.doi.org/10.5902/1984644435265

vocação ao universal e por isso identificada como capaz de autodeterminação. Recorrendo à etimologia grega, é esta autodeterminação reconhecida que dá à universidade seu status de autos - por si mesma - e de nomos - lei, regra ou região. Se este é o que rege o princípio da autonomia, não há como aceitar o seu oposto, a heteronomia - ser regido pelo outro.

Para Cury (1991, p. 27) "a autonomia (universitária) supões, pois, o espaço de uma ação criadora, socialmente responsável, e de uma produção científica reconhecida e avaliada". A afirmação de Cury acima resolve outro dilema, o da autonomia dialogada com a sociedade. A avaliação aparece como instrumento imprescindível para o diálogo entre a universidade e os diferentes setores da sociedade. E configura-se, portanto uma avaliação que propõe à universidade a reflexão sobre seu necessário diálogo com a sociedade.

Ao retomarmos esse debate sobre a autonomia universitária, salta aos olhos a postura do CEE/SP de afronta ao texto constitucional. O Conselho tem se colocado como o mandatário da organização curricular nas universidades públicas, desconsiderando possibilidades de diálogo e negociação. Resta, portanto, nos perguntar sobre as possíveis intenções com atitudes como essa.

A matéria da Revista Carta Educação de março de 2016², trazia à tona questões relevantes quanto à composição do CEE/SP. Segundo matéria, a maior parte dos membros desse Conselho tem fortes vínculos com o setor privado da educação. Alguns deles inclusive, com relações antigas com redes de ensino superior privado. Questionado pela reportagem sobre o assunto, o presidente do Conselho Francisco José Carbonari responde dizendo que as indicações desses membros do CEE/SP atendem à demanda de conhecimento técnico da área, ou seja, para ele a função desse órgão é exclusivamente técnica. Esse argumento é no mínimo questionável, tendo em vista a impossibilidade de separação entre técnica e política. Para nós, a resposta do presidente do Conselho aponta ainda para mais uma das incongruências do referido órgão, ou seja, sua sustentação regulamentada pela Lei 10.403 de 1971. Sobre esse último aspecto, importante ressaltar que um projeto de Lei apresentado por deputados estaduais em 2012 na Assembleia Legislativa, trata da redefinição da composição do CEE em maior conformidade com os textos atuais e 


\section{Autตaดูão}

ISSN: 1984-6444 | http://dx.doi.org/10.5902/1984644435265

com a dinâmica de uma sociedade democrática. No entanto, o projeto nunca foi a plenário para ser votado, apesar de ter sido aprovado em todas as instâncias por onde tramitou.

Ainda na reportagem da Folha de São Paulo de maio de 2014 que anunciava a ação do CEE sobre as universidades públicas paulistas, um dado merece destaque. $\mathrm{Na}$ linha de condução da reportagem, no sentido de coadunar com a proposta do Conselho Estadual de Educação, há a seguinte afirmação "O Saresp, exame estadual, mostra que $40 \%$ dos alunos se formam no ensino médio público sem os conhecimentos adequados em português". No contexto da reportagem, tal afirmação nos leva a deduzir que há uma relação direta entre formação de professores e desempenho dos estudantes nos exames de larga escala. Esta é uma dedução simplista por não apresentar os estudos que a sustentariam, além de não problematizar sobre outras condições e outros fatores que impactam na garantia do aprendizado e de bom desempenho dos estudantes de ensino médio no Estado de São Paulo. Além do que, o jornal induz o leitor à noção de que as universidades públicas - UNICAMP, UNESP e USP - são responsáveis pela formação dos professores da educação básica pública e que essa formação não está atendendo à qualidade do ensino da língua na rede pública do estado, revelada a partir dos resultados dos estudantes no SARESP.

Tomemos como pressuposto que seria possível avaliar qualidade da aprendizagem através do desempenho no SARESP, o que para nós é restritivo e limitador de qualquer análise que se proponha séria. Se essa possibilidade existisse, de antemão teríamos duas considerações que precisariam ser feitas. A primeira é que as três universidades juntas não formam professores suficientes para serem responsáveis pelo processo de aprendizagem de uma rede tão grande quanto a do Estado de São Paulo. Em uma notícia veiculada pelo governo do estado em seu site oficial, em 2017 foram contratados 93,5 mil professores da educação básica. Consideremos que a cada ano saiam por volta de 250 pedagogos formados nas três universidades públicas, que atuarão nos anos iniciais do ensino fundamental da rede estadual paulista. Isto seria apenas uma suposição, pois sabemos que nem todos vão atuar como professores e, dos formados que vão para esta atuação, nem todos se 


\section{T WsM entubará

ISSN: 1984-6444 | http://dx.doi.org/10.5902/1984644435265

dirigem para os anos iniciais, além disto, não necessariamente vão para a rede pública paulista. O estado de São Paulo, no ano de 2014, atendeu ao número de 2.180.111 matrículas no ensino fundamental de 9 anos. Mesmo considerando que as crianças atendidas nos anos iniciais seriam a metade deste número, seria impossível, com menos de 250 professores, haver a promoção escolar deste montante pelas três universidades públicas.

A segunda é que tal processo de culpabilização, via jornal de tamanha repercussão e que forma opiniões, produz efeitos diversos, e um deles é a perspectiva de que as universidades públicas, financiadas com dinheiro público, não estão produzindo mão de obra de qualidade e, consequentemente, não servem à sociedade. O discurso fortalece um movimento que cresce no sentido de desqualificar o trabalho de universidades públicas. Não queremos com isto afirmar que não há problemas no interior da instituição pública, assim como há em instituições particulares e tantas outras. O que frisamos neste momento é a ampliação do problema pela formação da opinião pública, de um ponto de vista que não está fundamentado em dados que nos leve minimamente a aceitar tais assunções.

A primeira versão da deliberação do CEE que se propunha orientar a formação de professores da educação básica, deixou de lado os profissionais da educação infantil. O silêncio em relação a esse profissional, aponta para um não reconhecimento dessa como a etapa inicial da educação básica.

\footnotetext{
Art. $3^{\circ}-$ A formação de professores poderá ser feita num mesmo curso para: I - anos iniciais do ensino fundamental, compreendendo do $1^{\circ} \stackrel{0}{\text { ao }} 5^{\circ}$ ano, e pré-escola;

II - anos finais do ensino fundamental, compreendendo do $6^{\circ}$ ao $9^{\circ}$ ano, e ensino médio.

Parágrafo único - A formação de professores para creches e para a educação especial e a de profissionais não docentes para as creches serão objeto de regulamentações próprias. (SÃO PAULO, 2012, p.1)
}

Com esta configuração deixa-se para outra regulamentação a atuação do professor na creche e restringe-se a formação de professores apenas a partir da préescola, ou seja, a partir da atuação junto à etapa da educação infantil que corresponde aos 4 anos de idade. Vale a pena elucidar que a obrigatoriedade dessa etapa da educação básica foi assegurada a partir da Lei 12796/2013 (que ajusta a LDB a 


\section{Usm Eutlagha}

ISSN: 1984-6444 | http://dx.doi.org/10.5902/1984644435265

atender a Emenda Constitucional 59 de 2011) que define a obrigatoriedade de matrícula das crianças a partir dos 4 anos de idade. Neste sentido, podemos supor, que esta inicial proposição da deliberação era o reconhecimento que o professor deve atuar a partir dos 4 anos de idade, quando se iniciaria o processo de escolarização. $E$ que a creche, que não se constitui como educação escolar obrigatória, não necessitaria de profissionais formados em nível de graduação. Isto nos remete à um debate sobre a especificidade do trabalho docente, e tal postura do CEE é assunção da não necessidade de formação do profissional que atua com bebês, em especial.

Outro aspecto da deliberação que chama nossa atenção é a definição dos tempos, dentre eles 800 horas para formação científico-cultural. Essas horas seriam caracterizadas por tempos de estudo, previstos nas disciplinas conforme o descrito no artigo 5:

Art. 5 - A formação científico-cultural tem por objetivo ampliar a formação obtida no ensino médio e aprofundar os conteúdos a serem ensinados na préescola e anos iniciais do ensino fundamental e incluirá na estrutura curricular: I - estudos da Língua Portuguesa falada e escrita, da leitura, produção e utilização de diferentes gêneros de textos, indispensáveis para o trabalho em sala de aula e para o registro e comunicação de sua experiência docente;

II - estudos de Matemática necessários tanto para as atividades de ensino como para o uso e produção de indicadores e estatísticas educacionais;

III- estudos de História sobre a constituição das grandes divisões sóciopolíticas tanto do Brasil como do mundo globalizado;

IV - estudos de Ciências Naturais incluindo a compreensão da evolução da vida, do corpo humano e seu crescimento, da saúde e da doença;

VI- utilização das Tecnologias da Comunicação e Informação (TICs) como recurso pedagógico e ferramenta para o próprio desenvolvimento intelectual e profissional;

VII - ampliação e enriquecimento da cultura geral incluindo experiências curriculares diversificadas que propiciem acesso, conhecimento e familiaridade com instituições e manifestações culturais, artísticas e científicas. (SÃO PAULO, 2012, p. 1-2)

Esta previsão parte do pressuposto de que os estudantes que se dirigem aos cursos de licenciatura apresentam uma lacuna em sua formação inicial, que deverá ser preenchida na universidade, por uma prática de formação compensatória. Apresenta também uma compreensão de dissociação entre conteúdo e metodologia, ou seja, sob o argumento do necessário domínio de conteúdo da disciplina que o futuro professor irá lecionar, se aponta para uma noção de que esse conteúdo deverá 


\section{Autuaŗão}

ISSN: 1984-6444 | http://dx.doi.org/10.5902/1984644435265

ser aprendido na retomada dos conceitos do ensino médio e não associado ao estudo das metodologias de ensino desses mesmos conceitos.

É importante analisar, sobre esta imposição pelo conteúdo explicitado, a compreensão de que um curso de formação pedagógico precisa tão somente de conteúdo do que será ensinado, e, talvez, de método de ensino. Nos voltemos ao que inúmeros estudos nos mostram, dentre eles estudos no campo da formação de professores (HELENA FREITAS, 1993; GERALDI, 1998, dentre muitos outros) ou no campo do currículo (SACRISTAN, 2013; GOODSON, 2001, dentre muitos outros) realizadas no campo teórico prático, que não existe prática dissociada de teoria. E não há teorias apenas direcionadas a técnicas de ensino, mas teorias que demonstram que ser professor exige conhecimentos em diferentes áreas de fundamentos.

Saviani (2009), ao retomar a história da formação de professores, apresenta os dois modelos que estiveram como subjacentes às propostas de cursos de formação. O primeiro é o modelo dos conteúdos culturais-cognitivos, em que "a formação do professor se esgota na cultura geral e no domínio específico dos conteúdos da área de conhecimento correspondente à disciplina que irá lecionar" (SAVIANI, 2009, p. 148). E o segundo é o modelo pedagógico-didático, em que "considera que a formação do professor propriamente dita só se completa com o efetivo preparo pedagógicodidático" (SAVIANI, 2009, p. 149). Ora um ou outro modelo predominavam e até hoje este é o dilema posto. E novamente este dilema está constituído, quando uma deliberação entoa um discurso pelo aumento quantitativo de conteúdo específicos de diferentes áreas de conhecimento, que supostamente serão objeto de conhecimento. E por que supostamente? Porque já aprendemos como lição de currículo que conteúdo e forma não se separam. Neste embate entre conteúdos culturais-cognitivos e trabalho com os conhecimentos pedagógico-didáticos, há a necessidade de retomar a visão de totalidade e dialética do que, no jogo das aparências, nos é apresentado como separados.

A deliberação foi apresentada em dia 14 de março do ano 2012 para representantes das universidades e deveria ser implementado a partir do ano seguinte. As universidades públicas se reuniram, chamadas pelas suas diferentes comissões de formação de professores internas, e discutiram encaminhamentos para 


\section{F WFH outroarao

ISSN: 1984-6444 | http://dx.doi.org/10.5902/1984644435265

responder à deliberação. Depois de um intenso movimento, conseguiram que o $\mathrm{CEE}$ abrisse espaço para uma reunião conjunta.

Nesse encontro, houve a proposta de que os docentes presentes, majoritariamente coordenadores de cursos de formação de professores das três universidades públicas paulistas, trabalhassem o documento apresentando sugestões de alteração ao texto. Por compreender que o documento carecia de discussão acerca dos princípios em que se pautava, ou seja, de que não se tratava de melhorar a redação ou do aprimoramento de alguns de seus artigos, o grupo de coordenadores dos cursos de Pedagogia demandou a professora Bernardette Gatti - conselheira recém indicada e que esteve presente nessa reunião ocorrida em janeiro de 2013 para que o CEE/SP abrisse audiências públicas, colocando em debate a Deliberação. A demanda foi acatada pelo plenário, no entanto, sem nenhum movimento nesse sentido, em 2014 o CEE publica uma nova redação da mesma deliberação.

A lei 126/2014, do ponto de vista macro, pouco alterou a anteriormente proposta. Incluíram a formação do professor da educação infantil, retirando a restrição da formação do professor da pré-escola. Outra alteração foi o aumento da carga horária de estágio no campo da gestão educacional. E em 2017, a deliberação se tornou 154/2017. Nesta versão, a distribuição da carga horária assim se configura:

I-600 (seiscentas) horas dedicadas à revisão e enriquecimento dos conteúdos curriculares do ensino fundamental e médio;

II - 1.400 (hum mil e quatrocentas) horas dedicadas ao estudo dos conteúdos específicos e dos conhecimentos pedagógicos que garantam a transposição didática ou outras mediações didáticas e a apropriação crítica desses conteúdos pelos alunos;

III - 400 (quatrocentas) horas de prática como componente curricular - PCC adicionadas às 1.400 horas do item anterior e distribuídas ao longo do percurso formativo do futuro professor, em conformidade com o item 2 da Indicação CEE № 160/2017, referente a esta Deliberação;

IV - 400 (quatrocentas) horas para estágio supervisionado;

V - 400 (quatrocentas) horas para formação nas demais funções previstas na Resolução CNE/CP no 01/2006. 


\section{T WsM Futbabुa}

ISSN: 1984-6444 | http://dx.doi.org/10.5902/1984644435265

Entretanto há uma atenção especial na alteração da configuração dos termos do curso, especificando as horas de atividade prática nos cursos, o que ficou conhecido como Prática como Componente Curricular (PCC). Na distribuição da carga horária, apresentada no artigo 4ํㅡㄹ há a destinação de 400 horas para atividades no componente do PCC, que seriam distribuídas nos componentes pedagógicos das horas destinadas ao estudos dos componentes específicos e pedagógicos. Segundo o texto que fundamenta a deliberação, ele é compreendido como...

o encontro do conhecimento sobre um determinado objeto de ensino, com o conhecimento pedagógico sobre como se aprende e como se ensina esse conteúdo. Constitui a dimensão prática, contextualizada e significativa de todos os conteúdos curriculares da formação docente, tanto aqueles específicos de uma área ou disciplina quanto aqueles dos fundamentos pedagógicos (SÃO PAULO, 2017, p. 4).

E é neste aspecto que mora uma discussão pertinente sobre a compreensão da relação teoria e prática.

Voltemos à compreensão do que seria a prática docente como base na formação docente apontado por Scheibe (2007). Tanto o aporte da necessidade de inserir conteúdos relacionados à educação básica, bem como as técnicas de ensino destes conteúdos, na formação de professores, reduzem a compreensão da docência como um praticismo técnico. E conflitam com o postulado pelas diretrizes curriculares nacionais para a formação inicial e continuada dos profissionais do magistério da educação básica, aprovada pelo CNE no Parecer CNE/CP 02/2015, no que se refere ao conceito de docência, aos princípios da relação ensino e pesquisa, bem como à relação teoria e prática. Esta leitura pode ser facilmente lida na deliberação pela ausência. Todas as referências estão no campo do domínio de conteúdos da educação básica, constantes no artigo $5^{0}$ que já foi citado anteriormente. Ou ainda, em outros aspectos do trabalho relacionadas às dimensões didático-pedagógicas como consta no artigo 6, já na versão da deliberação de 2017 - Deliberação CEE $154 / 17$.

Art. 6으 1.400 (hum mil e quatrocentas) horas de que trata o inciso II do artigo $4^{0}$ compreendem um corpo de conhecimentos educacionais, pedagógicos e didáticos com o objetivo de garantir aos futuros professores de pré-escola e dos anos iniciais do ensino fundamental competências especificamente voltadas para a prática da docência e da gestão do ensino: 


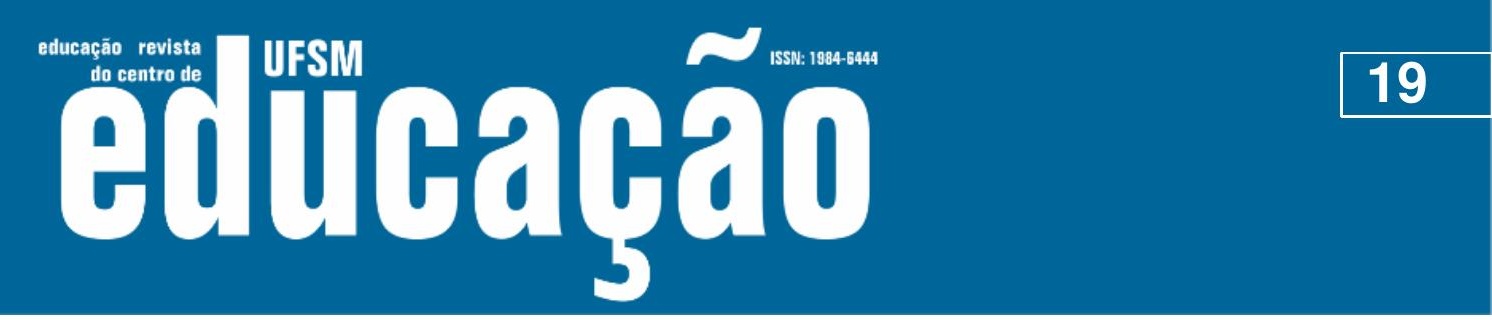

ISSN: 1984-6444 | http://dx.doi.org/10.5902/1984644435265

I - conhecimentos de História da Educação, Sociologia da Educação e Filosofia da Educação que fundamentam as ideias e as práticas pedagógicas; II - conhecimentos de Psicologia do Desenvolvimento e da Aprendizagem para compreensão das características do desenvolvimento cognitivo, social, afetivo e físico de crianças e adolescentes;

III - conhecimento do sistema educacional brasileiro, sua evolução histórica e suas políticas, para fundamentar a análise da educação escolar no país, bem como possibilitar ao futuro professor entender o contexto no qual vai exercer sua prática;

IV - conhecimento e análise das diretrizes curriculares nacionais, da Base Nacional Comum Curricular da Educação Básica, e dos currículos estaduais e municipais para educação infantil e o ensino fundamental;

V - domínio dos fundamentos da Didática que possibilitem: a) a compreensão da natureza interdisciplinar do conhecimento e de sua contextualização na realidade da escola e dos alunos; b) a constituição de uma visão ampla do processo formativo e socioemocional que permita entender a relevância e desenvolver nos seus alunos os conteúdos, competências e habilidades para sua vida; c) a constituição de habilidades para o manejo dos ritmos, espaços e tempos de aprendizagem, tendo em vista dinamizar o trabalho de sala de aula e motivar os alunos; d) a constituição de conhecimentos e habilidades para elaborar e aplicar procedimentos de avaliação que subsidiem e garantam processos progressivos de aprendizagem e de recuperação contínua dos alunos e; e) competências para o exercício do trabalho coletivo e projetos para atividades de aprendizagem colaborativa;

VI - conhecimento das Metodologias, Práticas de Ensino ou Didáticas Específicas próprias dos conteúdos a serem ensinados, considerando o desenvolvimento dos alunos, e que possibilitem o domínio pedagógico do conteúdo, bem como da gestão e planejamento do processo de ensino aprendizagem;

VII - conhecimento da gestão escolar na educação infantil e nos anos iniciais do ensino fundamental, com especial ênfase nas questões relativas ao projeto pedagógico da escola, regimento escolar, planos de trabalho anual, colegiados auxiliares da escola e famílias dos alunos;

VIII - conhecimentos dos marcos legais, conceitos básicos, propostas e projetos curriculares de inclusão para 0 atendimento de alunos com deficiência;

IX - conhecimento, interpretação e utilização na prática docente de indicadores e informações contidas nas avaliações do desempenho escolar realizadas pelo Ministério da Educação e pela Secretaria Estadual de Educação. (SÃO PAULO, 2017, p. 2-3)

Se adentrarmos numa leitura analítica do artigo acima, podemos inferir que as postulações estão no campo do fazer técnico. É relevante tais conhecimentos para os futuros professores, mas a deliberação centraliza a regulamentação em apenas dois grandes aspectos como essenciais à formação, a saber: um do campo dos conhecimentos da educação básica e outro no campo de competências para ensinar. O fato é que os princípios que regem a formação e constam nas Diretrizes Curriculares Nacionais para o Formação de Professores de 2015, não aparecem neste momento, levando-nos à interrogação das intenções com esta deliberação. 


\section{A Ism Eutlagha}

ISSN: 1984-6444 | http://dx.doi.org/10.5902/1984644435265

Alia-se a esta interrogação o fato do movimento interno de chegada da deliberação no interior da universidade e a dinâmica de interferência nos projetos pedagógicos. Quando do processo de reorganização do curso para responder à deliberação, os cursos de licenciatura foram orientados a preencher uma planilha de referências bibliográficas de todas as disciplinas. Ao final deste processo, vários cursos tiveram que readequar estas referências de acordo com o que o CEE defendia como essencial para a formação de professores. Tal ação nos levou a questionar ainda mais o quanto não estávamos diante de uma prática de ingerência na autonomia universitária.

O que está em jogo e muito bem retratado nas ações mais recentes do CEE referentes aos cursos de formação de professores, e bem retratado na reportagem da Folha citada no início desse artigo, é a relação de poder que se tenta estabelecer sobre as Universidades públicas paulistas. Ao retomar que tais deliberações ferem o princípio da autonomia, não o estamos tomando apenas do ponto de vista legal, mas enfatizando que ações como essa ferem o princípio do espaço da universidade como o de circulação e produção de conhecimentos diversos. A deliberação do CEE apresenta um forte caráter de interferência na construção curricular a ser produzida, no conteúdo a ser ministrado, nos tempos específicos e no superdimensionamento da responsabilidade das universidades estaduais.

\section{Conclusão}

A iniciativa de discorrer neste artigo os acontecimentos da relação Conselho de Educação do Estado de São Paulo com as universidades públicas paulistas no contexto da publicação da Deliberação 111/12, nos levam o olhar também para contextos mais amplos. Não é possível nos restringir apenas ao quadro interno das faculdades de educação para narrar esta condução do CEE. O contexto maior em que são elaboradas as deliberações incluem: movimento para a alteração do princípio da universidade pública e gratuita; movimento por uma educação mais técnica; movimento para a entrada de forma mais enfática dos grupos de iniciativa privada na educação pública. 


\section{F HEM efituaráo

ISSN: 1984-6444 | http://dx.doi.org/10.5902/1984644435265

Vivemos nos últimos anos uma avalanche de ações e ataques ao caráter público e gratuito das universidades. A assunção de que a universidade não está formando adequadamente os professores que atuam na rede pública de ensino é uma delas e consequentemente, há necessidade de alteração curricular determinada por experts que, supostamente, detém um conhecimento sobre como proceder para esta melhoria - na centralização da formação docente. E deste primeiro aspecto contextual advém o segundo aspecto da ênfase à educação centralizada na técnica. Embates nacionais em torno de uma educação neutra, sem vínculos partidários e ideológicos, têm centrado o debate nacional, incluindo aí questionamentos sobre o trabalho com gênero na escola, bem como de posicionamentos sociais, históricos que possam desconstruir certa lógica linear e a ideia que a escola é lugar de aprender alguns conhecimentos cientificamente comprovados, preferencialmente no campo da produção das ciências exatas.

E por fim, o contexto da entrada da iniciativa privada na educação pública, a partir de dois argumentos que vem sendo priorizados: o da necessária melhoria da qualidade e o da necessária redução do estado em seus gastos com investimentos e bens públicos, como educação.

Construir um olhar crítico sobre o tema em questão nos leva a reafirmar alguns princípios caros ao processo democrático e em especial à construção de uma universidade pública, gratuita, responsável pela formação de professores, solidamente constituída, que centre seus processos de reflexão na prática social contraditória, complexa e que não requer apenas um agir técnico, descomprometido com os problemas sociais que vivemos. Toda forma de atuação do professor é uma forma política, comprometida com sujeitos eticamente, em que precisamos responder ética e responsavelmente.

\section{Referências}

BRASIL. Lei de Diretrizes e Bases da Educação Nacional. Lei número 9394, 20 de dezembro de 1996. 


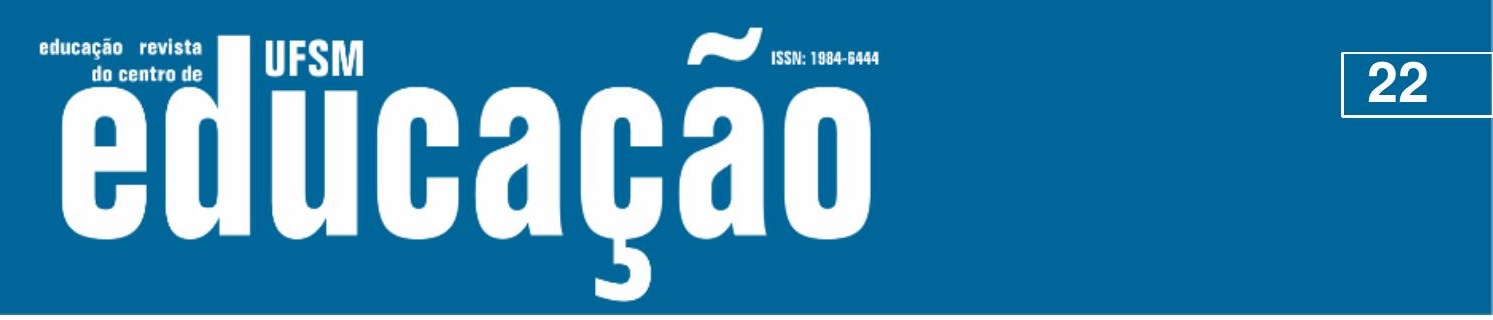

ISSN: 1984-6444 | http://dx.doi.org/10.5902/1984644435265

BRASIL. Conselho Nacional de Educação. Diretrizes Curriculares Nacionais para o Curso de Pedagogia. Parecer CNE/CP 5, 13.12.2005. Brasília, 2005. Disponível em http://portal.mec.gov.br/cne/arquivos/pdf/pcp05_05.pdf.

BRASIL. Conselho Nacional de Educação. Define as Diretrizes Curriculares Nacionais para a formação inicial em nível superior (cursos de licenciatura, cursos de formação pedagógica para graduados e cursos de segunda licenciatura) e para a formação continuada. Resolução CNE/CP n. 02/2015, de 1ำ de julho de 2015. Brasília, Diário Oficial [da] República Federativa do Brasil, seção 1, n. 124, p. 8-12, 02 de julho de 2015. Disponível em: http://portal.mec.gov.br/index.php?option=com_docman\&view= download\&alias=17719-res-cne-cp-002-03072015\&category_slug=julho-2015pdf\&Itemid=30192.

BOURDIEU, Pierre. Esboço para uma auto-análise. Lisboa; Edições 70, 2005.

CONSELHO impõe mais aula prática na pedagogia de USP, UNESP E UNICAMP, Folha de São Paulo, 24 maio, 2014. Disponível em https://www1.folha.uol.com.br/educacao/2014/05/1463037-conselho-impoe-maisaula-pratica-na-pedagogia-de-usp-unesp-e-unicamp.shtml.

CURY, Carlos Roberto Jamil. A questão da autonomia universitária. Universidade e Sociedade, ano 1, n. 2, p. 25-29, nov. 1991.

DOURADO, Luiz Fernandes. Diretrizes curriculares nacionais para a formação inicial e continuada dos profissionais do magistério da educação básica: concepções e desafios. Educação e Sociedade., Campinas, v. 36, no. 131, p. 299-324, abr.-jun., 2015

FREITAS, Helena Costa Lopes de. O Trabalho como Princípio articulador da Teoria-Prática: Uma análise da Prática de Ensino e Estágios Supervisionados na Habilitação Magistério do Curso de Pedagogia da FE-UNICAMP. 1993. Tese (Doutorado em Educação). Faculdade de Educação, UNICAMP, Campinas.

GERALDI, Corinta Maria Grisolia. (Org.). Cartografias do trabalho docente: Professor (a)-Pesquisador(a). Campinas/SP. Mercado de letras. 1998.

GOODSON, Ivor. O currículo em mudança: Estudos na construção social do currículo. Porto - Portugal. Porto. 2001.

SACRISTAN, Jose Gimeno. O que significa currículo? In: SACRISTÀN, J. Gimeno (Org.) Saberes e incertezas sobre o currículo. Tradução: Alexandre Salvaterra; Revisão técnica: Miguél Arroyo. Penso, Porto Alegre, 2013. 


\section{I wsm Ellibahá}

ISSN: 1984-6444 | http://dx.doi.org/10.5902/1984644435265

\section{Notas}

1 O documento pode ser localizado no seguinte endereço: http://www.lite.fe.unicamp.br/grupos/formac/comiss\%E3o_nacional_de_reformula\%E7\%E3.htm.

2 “Conselho Estadual de Educação de São Paulo carece de democratização". Reportagem de Marco Antônio Miguel em 24 de março de 2016. (disponível em www.cartaeducacao.com.br/reportagens/conelho-estadual-desao-paulo-carece-de-democratizacao. Acessado em 30/04/2018) 